\title{
Measurement and calculation of surface temperature on tyre samples
}

\author{
Frederik Bartz', Frederik Bartz, S. Gehrmann², S. Augustin'2, V. Ackermann², T. Fröhlich² \\ ${ }_{1}^{1}$ Dr. Ing. h.c. F. Porsche AG, Porschestrasse 911, 71287 Weissach, Germany, \\ 2 Dr. Ing. h.c. F. Porsche AG, Porschestrasse 911, 71287 Weissach, Germany \& TU IImenau, Institute \\ PMS, Gustav-Kirchhoff-Str. 1, 98693 IImenau, Germany, stephan.gehrmann@porsche.de, \\ silke.augustin@tu-ilmenau.de,v.ackermann@tu-ilmenau.de, thomas.froehlich@tu-ilmenau.de
}

\begin{abstract}
Summary:
For a better understanding of the temperature behaviour of vehicle tyres, measurements have been carried out on a specially developed test bench. Various measuring instruments have been used to determine the surface temperature. Different influences such as the external radiation effects have been investigated. Furthermore, the heat transport in the tyre samples and the exchange with the surrounding environment has been estimated by means of numerical simulations.
\end{abstract}

Keywords: surface temperature, simulation of the radiation exchange, heat transfer in tyre samples

\section{Introduction}

With the increasing performance of vehicles and a more compact vehicle package, the external influences on the temperature of vehicle tyres are sometimes increasing. Too high temperatures can damage the tyre [1] - [3]. Therefore, the temperature behaviour under different environmental conditions has been investigated on a test bench using tyre samples. In addition, the heat transport in the test stand was numerically calculated. In this way, the different power ratios of the heat flows could be broken down. Furthermore, measured surface temperatures were compared with the simulations.

It is usually assumed that the temperature of the measuring object (solid body) is different from that of the surrounding fluid. Consequently, the surface temperature of a measurement object is located at a point of discontinuity in the temperature profile. Hence, measuring the surface temperature is a difficult task. In this lecture, the determination of the surface temperature without using a contacting thermometer will be addressed. The reason for these investigations are the changes in heat flux density resulting from the contact measurement. The difference between the undisturbed and disturbed heat flux density makes it difficult to draw conclusions about the correct surface temperature, see Fig. 1 [4].

In addition, previous investigations have shown that the reproducible installation of thermometers on the surface cannot always be guaranteed [5]. Furthermore, it is not always possible to contact the surface directly in every measuring situation (e.g. rotating components).
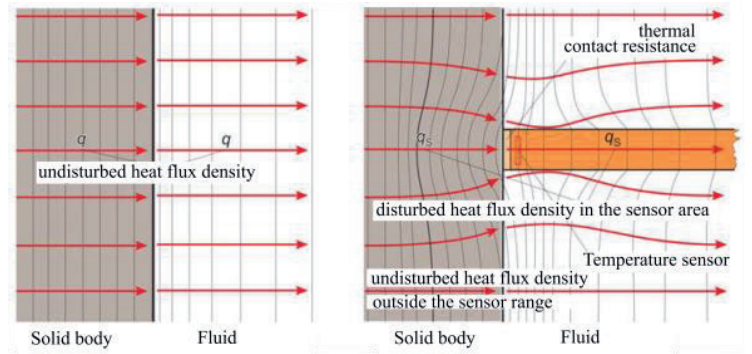

Fig. 1. Comparison of undisturbed and disturbed heat flux density [4]

\section{Measurement and calculation methods}

Due to the conditions mentioned above, the challenge arises to measure the surface temperature without contact or to determine it by calculation using suitable methods. In the submitted lecture, three different strategies are presented. In the first approach, the surface temperature is measured by means of radiation thermometers. For the second and third approach, the surface temperature is calculated. In the second approach, the surface temperature is determined by extrapolation from several temperature measuring points in the test object.

In the third approach, the calculation is based on numerical FEM methods of the heat transport and the fluid dynamics. All three methods have different advantages and disadvantages. For the radiation temperature measurement the correct emission coefficient of the surface is of particular importance. [4] 
To calculate the surface temperature and the heat flow, the thermal conductivity and other important parameters of the system components (tyre sample, adhesive, intermediate layers, etc.) must be known [4], [6]. Further influencing variables and their uncertainty contributions are shown in the full article.

The metrological investigations were carried out on a specially developed test bench (see Fig. 2 ). This test bench is able to reproduce the fundamental types of heat transfer (heat conduction, convection, and heat radiation). Reproducible measuring conditions have already been proven in earlier studies [5], [7]. The measurement objects are from different tyres. The emission coefficient and thermal conductivity of these samples have been determined in experimental investigations. The respective methods and results are also presented in the article [8].

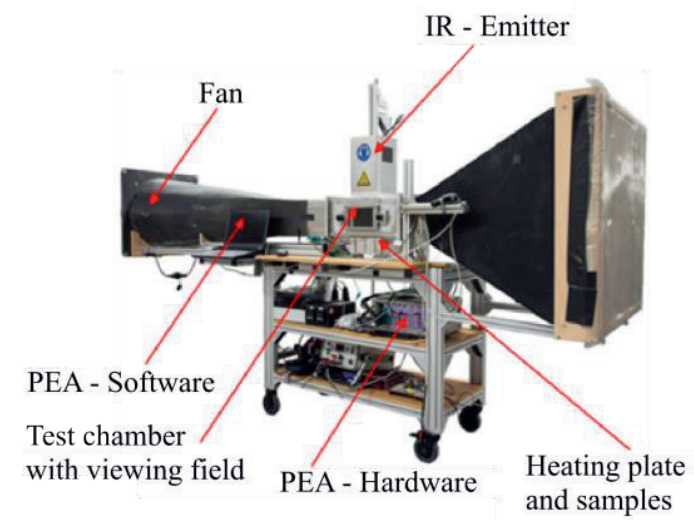

Fig. 2. Test bench for measuring the surface temperature

\section{Results}

The results for different test parameters on the test bench are presented in the submitted paper. The measured and calculated surface temperatures are compared with each other. Surface temperatures, which deviate from each other, are discussed and analysed.

It is shown that an additional external radiation source increases the differences between the extrapolated temperature and the temperature measured by radiation thermometers. These differences probably result from reflected radiation components in the radiation temperature measurement. For extrapolation based on several temperatures, the positioning of the individual thermocouples and the resulting difference is not reliable. The influences of an external radiation source and the temperature profile in the samples have been further investigated with FEM calculations [9]. By calculating the view factors, the proportions of emitted and reflected radiation components could be determined.

Both the test bench investigations and the numerical calculations have contributed to a better understanding of measuring surface temperatures. With the help of the investigations different influencing factors could be shown, which will be considered in future measurements.

\section{Future prospect}

In further investigations, which are part of the future prospect, an additional strategy for the contactless determination of the surface temperature is presented. Specially developed heat flow sensors could be used for this purpose. The thermal conductivity of actual heat flow sensors does not correspond to the required thermal conductivity. The different thermal conductivities result in different thermal resistances, which strongly influence an accurate measurement of the heat flow. The development of new heat flow sensors should compensate this disadvantage. The surface temperature is then determined from the measured heat flow and a known temperature within the measured object.

\section{References}

[1] Kraftfahrt-Bundesamt (KBA): Downsizing - nicht in jedem Segment ein Thema. KBA Fahrzeugstatistik, 08/2018.

[2] M. Trzesniowski, Handbuch Rennwagentechnik Fahrwerk, 2. Auflage, Springer Vieweg, 2019.

[3] Continental Reifen Deutschland GmbH: Reifenschäden: Ursachen und Vermeidung, In PkwReifen 2013 - 14. Technisches Handbuch, Continental Reifen Deutschland GmbH, 09/2013.

[4] Bernhard F.: Handbuch der Technischen Temperaturmessung. VDI-Buchreihe. Springer Vieweg, Berlin, Heidelberg, 2014

[5] Gorajski M., Entwicklung eines indirekten Messverfahrens zur Untersuchung des statischthermischen Messfehlers von OberflächenThermoelementen, Masterarbeit, Porsche AG, TU IImenau, 2016

[6] Baehr H.D., Stephan K.: Wärme- und Stoffübertragung. Springer Vieweg, 2016

[7] Schweickhardt J.: Optimierung eines Probenträgers zur Ermittlung der Messunsicherheit bei der Oberflächentemperaturmessung, Bachelorarbeit, Porsche AG, Hochschule Esslingen, 2019

[8] Manara J., Arduini M., Hemberger F.: Bestimmung des Emissionsgrads und der Wärmeleitfähigkeit, ZAE Bericht, Report ZAE 2-0119-02 und Report ZAE 2-0719-03, 2019

[9] Ackermann V., Numerische Berechnung des Einflusses verschiedener Faktoren auf die Oberflächentemperatur von Fahrzeugreifen, Masterarbeit, TU IImenau, 2020 